\title{
Petróleo, imprensa e luta pelo desenvolvimento econômico: jornais "liberais" cariocas e a política econômica do Segundo Governo Vargas
}

Luis Carlos Passos Martins*

Resumo: O presente artigo irá analisar o posicionamento da chamada grande imprensa liberal do Rio de Janeiro - aqui representada pelos jornais O Globo (OG), O Jornal (OJ), Correio da Manhã (CM) e Jornal do Brasil (JB) - durante o processo de criação da Petrobras (1951-1953). Tal programa foi extremamente controverso, envolvendo um intenso debate sobre o projeto de desenvolvimento do governo (papel do Estado e do capital estrangeiro, em especial), e também uma disputa política em torno do tema do nacionalismo econômico, no qual o programa varguista foi acusado de "entreguista" por não incorporar inicialmente o monopólio estatal do petróleo, e a UDN aderiu à tese do monopólio apenas para se opor a Vargas. Dessa maneira, tal assunto é muito pertinente para discutir o posicionamento dos jornais, não apenas na questão do petróleo, mas também quanto às doutrinas econômicas nele envolvidas (liberalismo, nacionalismo, desenvolvimentismo), além de permitir avaliar melhor as interpretações tradicionais da historiografia sobre a relação entre imprensa e política no período.

Palavras-chave: Imprensa. Vargas. Desenvolvimentismo. Liberalismo.

\footnotetext{
* Professor Adjunto do curso de História da PUCRS. Doutor em História das Sociedades Ibero-americanas e professor do curso de Especialização em Política Internacional da Pontifícia Universidade Católica do Rio Grande do Sul - PUCRS. E-mail: luismart86@terra.com.br
} 
Petróleo, imprensa e luta pelo desenvolvimento econômico:...

\section{Introdução}

\section{Imprensa e política no Segundo Governo Vargas}

A imprensa é considerada um dos principais atores da cena política no Segundo Governo Vargas, especialmente no que se refere ao seu desfecho trágico e prematuro. Para muitos autores, inclusive, a oposição sistemática e até intransigente que os grandes jornais fizeram ao presidente foi um dos principais fatores de desestabilização do mesmo. ${ }^{1}$

Dentre os principais "conspiradores" da grande imprensa, normalmente são citados jornais como o Correio da Manhã, O Jornal, $O$ Globo e $O$ Estado de $S$. Paulo. O interessante quando olhamos esta amostra mais atentamente é que predominam jornais sediados na Capital Federal e considerados "liberais". ${ }^{2}$ Essa predominância, porém, não é gratuita. Em primeiro lugar, porque a imprensa carioca dos anos 50 era a mais dinâmica e influente do Brasil. Localizada na cidade-sede do poder político nacional, compunha-se de uma gama muito variada de impressos, com jornais tradicionais e de forte combatividade pública. Em segundo lugar, porque quando analisamos os motivos apontados para justificar tal oposição, um dos principais argumentos é a diferença que oporia Vargas e os grandes jornais na condução de sua política econômica: Getúlio seria o portador de um programa econômico nacionalista, que pregava ampla intervenção do Estado na economia e era hostil ao capital estrangeiro, defendendo um desenvolvimento capitalista autônomo; já a grande imprensa - partidária do liberalismo econômico - defendia a não intervenção estatal na economia, o máximo de liberdade ao fluxo de capital e mercadorias e, assim, a manutenção do país como produtor de bens primários capazes de lhe permitir maiores vantagens no comércio internacional.

No que se refere à interpretação do governo Vargas como nacionalista e anti-imperialista, segundo Fonseca (2002), essa versão foi elaborada por intelectuais ligados ao ISEB, que presenciaram ou foram participantes dos acontecimentos, como Celso Furtado, Hélio Jaguaribe e Nelson Werneck Sodré. Atualmente, mesmo os autores que defendem o "nacionalismo" de Getúlio em seu segundo 
mandato, sustentam a existência de um programa industrializante e desenvolvimentista (DRAIBE, 1985; FONSECA, 2002; BASTOS, 2009), mas que não seria hostil ao capital estrangeiro e não pregaria a estatização da economia, não sendo, dessa forma, autárquico ou anti-imperialista. ${ }^{3}$

Já quando indagamos pela origem da leitura sobre o posicionamento dos jornais, dois autores se destacam. Dentre eles, encontramos o brasilianista Thomas Skidmore. Mesmo contestando o "nacionalismo" do segundo mandato de Getúlio, ele identificou os grandes jornais brasileiros como filiados à corrente "liberal ou neoliberal" e, dessa forma, pouco entusiasta com projetos desenvolvimentistas que promovessem a industrialização com ampla intervenção estatal na economia (SKIDMORE, 1996, p. 118). Embora faça uma generalização em seu livro, Skidmore cita diretamente apenas dois jornais: O Globo e "o vasto império editorial de Assis Chateaubriand, os Diários Associados” (1996, p. 118).

Outro historiador que apresenta uma interpretação semelhante é Nelson Werneck Sodré, em seu livro, hoje clássico, História da Imprensa do Brasil. Em linhas gerais, esse autor defendeu que os grandes jornais brasileiros fizeram uma verdadeira campanha contra Vargas, porque ele levou adiante medidas que favoreciam a independência econômica do Brasil e contrariavam os interesses do imperialismo. Para esse autor, a grande imprensa brasileira era porta-voz dos interesses do capital internacional, o que levou a uma verdadeira ação conspirativa dos grandes jornais contra Getúlio "[...] pela necessidade de serem concedidas [...] facilidades para o desenvolvimento dos negócios dos monopólios, em nosso país” (SODRÉ, 1983, p. 403).

Um dos exemplos mais citados para comprovar essa interpretação é o posicionamento da grande imprensa sobre o programa do petróleo de Vargas. Sodré, por exemplo, afirma:

O imperialismo cedo percebeu que era imprescindível liquidar a parcela nacionalista da política de Vargas. Para isso, montou, à base das agências de publicidade, gigantesca e persistente campanha antinacionalista, visando impossibilitar a solução estatal do petróleo (SODRÉ, 1983, p. 400-401). 
Petróleo, imprensa e luta pelo desenvolvimento econômico:...

Disso resultou uma extraordinária "campanha da imprensa "[...] mobilizada pelas agências de publicidades norte-americanas" contra os defensores do monopólio estatal do petróleo (SODRÉ, 1983, p. 400-401).

Mesmo variando em alguns pontos, essa explicação teve grande respaldo entre os especialistas do período, sendo ainda hoje bastante aceita, ${ }^{4}$ como podemos notar com base na análise dos verbetes do Dicionário Histórico-Biográfico Brasileiro 5 sobre o posicionamento dos jornais pesquisados frente à criação da Petrobras. Em relação ao Jornal do Brasil, não encontramos referências diretas. Mas, já a respeito do Correio da Manhã, o DHBB afirma que esse periódico foi "inteiramente contra o monopólio estatal do petróleo", recordando ainda uma entrevista publicada pelo $C M$ com o Mr. Anderson, presidente da Standard Oil, "em que chegava a defender, com base em seus pressupostos liberais, um princípio de reciprocidade no que se referia à exploração do petróleo no Brasil, da mesma forma que os brasileiros o poderiam fazer nos Estados Unidos" (DHBB, 2001, p. 1629). ${ }^{6}$ Sobre O Jornal, o mesmo DHBB defende que foi a diferença de percepção de Chateaubriand e de Getúlio sobre o papel do capital estrangeiro que levou o afastamento do dono dos Diários Associados do governo, o que ficou mais transparente no caso do petróleo (DHBB, 2001, p. 2863). Por fim, no que se refere ao O Globo, o DHBB, além de considerar esse jornal como "o principal porta-voz da linha neoliberal", defensor do "capital estrangeiro, cujo ingresso era considerado benéfico na medida em que concorria para o enriquecimento do país", defende que ele desencadeou "também violenta campanha contra a Petrobras” (DHBB, 2001, p. 2863).

Curiosamente, apesar de toda a aceitação dessa interpretação sobre a relação entre a grande imprensa e o programa econômico do Segundo Governo Vargas (em especial, o projeto da Petrobras), não temos pesquisas empíricas a respeito do tema. O ponto de vista de Sodré e Skidmore é baseado fundamentalmente em "impressões gerais" sobre o comportamento dos jornais e em relatórios parlamentares que denunciavam a forte presença da publicidade estrangeira no seu financiamento. Além disso, os demais trabalhos que aceitaram ou endossaram essa explicação igualmente não a submeteram a uma pesquisa sistemática. Lacunas que, por si só, já justificam o tema deste trabalho. 


\section{O programa do petróleo, entre nacionalismo e desenvolvimentismo}

O Programa do Petróleo que deu origem à Petrobras foi um dos mais polêmicos do Segundo Governo Vargas. A solução do problema dos combustíveis fósseis esteve entre as prioridades que Getúlio apresentou à sua Assessoria Econômica da Presidência da República (AEPR), ${ }^{7}$ envolvendo, durante cerca de oito meses de trabalho, o esforço de seus principais integrantes. Essa prioridade se justifica por motivos políticos, porque o tema era central nas discussões públicas desde o governo Dutra e fez parte dos compromissos da campanha eleitoral de Vargas. Mas também se fundamentou em razões econômicas: o consumo de petróleo, apesar de ainda modesto no Brasil, crescia em média 20\% ao ano desde 1945 e, em 1951, já comprometia 13\% das importações brasileiras, indicando forte risco de racionamento.

O resultado do trabalho da Assessoria foi apresentado por Vargas ao Congresso, no dia 6 de dezembro de 1951, através da Mensagem Presidencial no. 469/51. O "programa do petróleo" estava dividido em dois projetos: um criando a Petróleo Brasileiro S.A. - ou simplesmente Petrobras - e outro estabelecendo os seus recursos financeiros. A nova empresa seria uma sociedade de economia mista, responsável pela exploração e produção de óleo cru e pela administração das refinarias e da frota de navios petroleiros do governo federal. Foi projetado para a sua viabilização um capital de US $\$ 500$ milhões, cuja obtenção deveria ser efetuada através de uma fórmula bastante engenhosa que incluía as propriedades da União sobre o setor petrolífero (jazidas, refinarias, equipamentos, navios), a transferência de alíquotas tributárias para a companhia e a criação de novos impostos, além da participação do investidor privado, embora de forma minoritária e compulsória.

Este projeto facultava à Petrobras amplo domínio sobre a atividade petrolífera nacional, ao mesmo tempo em que garantia o controle acionário da empresa à União, que deveria deter, no mínimo, $51 \%$ das ações com direito a voto. Não foi estabelecido o monopólio estatal de direito e permitido a participação de capital privado e estrangeiro, mesmo que limitado ao máximo de 15\% do total. 
Petróleo, imprensa e luta pelo desenvolvimento econômico:...

A historiografia especializada aponta três razões básicas que orientaram Vargas e a sua Assessoria em direção a essa fórmula: a) questões políticas, pois Getúlio teria evitado abordar diretamente o monopólio estatal do petróleo, para não provocar a rejeição da ala liberal do Congresso (COHN, 1968, p. 131); b) o pragmatismo do presidente, que o levou a optar por uma empresa de economia mista por considerá-la mais flexível do que uma autarquia (WIRTH, 1973, p. 171; PEREIRA, 1975, p. 99), e c) o próprio projeto de desenvolvimento de Vargas, que, conforme a literatura especializada em economia, seria desenvolvimentista ou nacional-desenvolvimentista, não sendo, assim, incompatível com investimentos privados e estrangeiros nos setores estratégicos, sempre que pudesse submetê-los às diretrizes do Estado.

O problema, contudo, foi que as precauções políticas e econômicas acabaram gerando efeitos não previstos: o programa do petróleo de Getúlio foi antes acusado de "entreguista" do que de "nacionalista" (MIRANDA, 1983, p. 269), recebendo a oposição dos grupos que há tempos lutavam pelo monopólio estatal do petróleo, reforçados pela UDN. Esse partido resolveu pegar carona na popularidade da tese do monopólio estatal e propôs uma nova companhia, a Empresa Nacional do Petróleo (Enape), que não só incorporava oficialmente o monopólio, como ainda determinava a encampação de todas as refinarias privadas em funcionamento ou já concedidas no Brasil.

Fora do Congresso, a oposição não foi menos ativa. Além da reação contrária da "ala nacionalista" do Exército (COHN, 1968, p. 138), o programa de Vargas recebeu a hostilidade da Campanha do "Petróleo E Nosso" que, através do Centro de Defesa do Petróleo e da Economia Nacional que a liderava (Cedpen), ${ }^{8}$ condenou a Petrobras por "tratar-se simplesmente de um projeto entreguista" (MIRANDA, 1983, p. 270).

Para evitar que o seu plano fosse rejeitado ou mesmo transfigurado na Câmara, Vargas aceitou negociar e fez um acordo com as lideranças partidárias, segundo o qual o monopólio estatal seria incluído oficialmente na Petrobras, eliminado do corpo de acionistas pessoas jurídicas de direito privado que tivessem sócios estrangeiros. Mas o governo manteve a participação do capital privado, 
as concessões às refinarias particulares e a exclusão do comércio atacadista do monopólio, procurando preservar o que pudesse da fórmula original (WHIRT, 1973, p. 182; COHN, 1968, p. 155).

Como resultado do acordo parlamentar, o novo projeto foi aprovado em primeira instância na Câmara no dia 23 de setembro de 1952, com 21 artigos a mais do que os 31 originais. Mas teve o seu caminho barrado no Senado, onde o menor compromisso com o nacionalismo permitiu que os congressistas tentassem modificar a companhia com emendas liberalizantes (COHN, 1968, p. 165). O projeto só voltou ao Palácio Tiradentes em junho de 1953, para - depois de retiradas as emendas liberalizantes do Senado - ser definitivamente aceito, em setembro do mesmo ano.

No dia 3 de outubro, o presidente sancionou a Lei $\mathrm{n}^{\circ} 2.004$ que criava a Petrobras como uma empresa mista da qual a União tinha o domínio das ações e que deveria explorar, em caráter monopolista, todas as etapas da indústria do petróleo brasileiro, com exceção da distribuição e das refinarias já concedidas. Em suma, estabelecia-se o monopólio parcial do petróleo, que ficou no meiotermo entre a proposta original de Vargas e a tese do monopólio estatal integral defendido pelo Cedpen.

\section{A criação da Petrobras: o difícil caminho entre "entreguismo" e "nacionalismo xenófobo"}

Os jornais pesquisados deram uma enorme atenção aos dois projetos de Vargas relativos ao petróleo, que receberam ampla cobertura jornalística durante a sua discussão nas Câmaras parlamentares. ${ }^{9}$

Desses periódicos, é no $J B$ que encontramos a menor receptividade ao programa, com pouco destaque no espaço informativo. ${ }^{10}$ Já nos editoriais, o periódico demonstrou ceticismo. No dia 10 de dezembro, criticou o projeto por implicar em aumento de impostos sobre combustíveis e automóveis, afirmando que "[...] no momento presente, quando tudo é pretexto para majorar preços e tornar a vida mais ainda mais difícil, impõe-se grande cautela na criação ou aumento de novos tributos" (JB-10/12/51, 1/5). 
Petróleo, imprensa e luta pelo desenvolvimento econômico:...

Fazendo uma síntese, podemos dividir os argumentos do $J B$ em dois pontos. O primeiro deles é a própria carência de recursos internos para levar adiante empreendimento tão custoso. Por isso, não seria possível abrir mão do capital e da técnica estrangeiras, o que Vargas acabou fazendo com um "projeto de cunho nacionalista". A segunda questão fica por conta da própria natureza da exploração de petróleo, na medida em que ela, por não oferecer garantia de sucesso, não dava segurança sobre o retorno dos investimentos, ainda mais em se tratando de um organismo estatal, moroso e burocrático (JB-05/02/52-1/5).

O Jornal demonstra uma posição bem particular em relação ao programa do governo. Em seus espaços informativos, dá enorme destaque aos projetos do presidente Vargas, os quais tiveram vasta visibilidade na capa do periódico, sendo inclusive a manchete da edição de 7 de dezembro. Apresenta, também, uma leitura positiva das propostas. ${ }^{11}$ Nos seus espaços de opinião, porém, a receptividade é bem menor. No editorial que trata do lançamento do programa, OJ procura ressaltar que o modelo encontrado por Vargas é uma "solução nacionalista", mas observa que ele irá implicar prejuízo à população, com aumento do custo de vida. De qualquer maneira, termina afirmando: "O presidente da República, dentro do seu programa de nacionalismo econômico, concebeu um plano que se ajusta à teoria dos empreendimentos dessa natureza" (OJ08/12/51-1/4). Em termos doutrinários, porém, esse diário toma uma posição coerente com o seu compromisso tradicional com a defesa do sistema de concessão à iniciativa privada na exploração petrolífera, conforme deixa claro quando elogia o modelo aplicado pelo Canadá e pelo Peru (OJ-27/03/52-1/4).

De qualquer maneira, o $J B$ e $O J$ parecem se aproximar no que se refere à sua discordância quanto ao projeto da Petrobras, tanto pela questão do aumento dos tributos quanto pela exclusão ou pouca participação do capital estrangeiro no mesmo, embora o segundo periódico demonstre maior aceitação do programa.

O Correio e O Globo tomaram uma posição diferente, sendo mais receptivos à proposta do governo. $\mathrm{O} C M$ dá amplo destaque ao lançamento do programa em seu espaço informativo e opinativo. Em seus editoriais, embora apresente reparos aos projetos do Executivo, ${ }^{12}$ elogia a proposta, tanto pela iniciativa em solucionar o 
problema quanto pela fórmula adotada, que apresenta uma boa combinação entre a eficácia e a defesa dos interesses nacionais, através de "um estatismo moderado" que permite "aos acionistas particulares a participação na administração" (CM-08/12/51-1/4).

A posição de $O$ Globo será ainda mais positiva ao programa do governo. A reportagem que repercute o anúncio das medidas é manchete no dia 7 de dezembro ("Afinal, o Brasil vai explorar o seu ouro negro!", OG-07/12/51-1/2), enquanto o editorial, que aborda o tema no mesmo dia, ocupa a capa do jornal e é um apelo direto ao Congresso para que vote e aprove logo os projetos ("O que o Brasil espera agora do Congresso", OG-07/12/51-1/1).

Em seu segundo editorial sobre o tema, $O G$ defende abertamente a fórmula adotada por Vargas, de uma maneira, a primeira vista, surpreendente, pois endossa os limites aos investimentos alienígenas, argumentando que eles provocam conflitos de interesse na exploração petrolífera. Segundo o jornal:

[...] julgamos que a solução adotada pelo Presidente Vargas é das mais acertadas. Assegurando, de um lado, a exploração do nosso petróleo afasta, do outro, choques e desentendimentos de consequências imprevisíveis $(O G-10 / 12 / 51-1 / 1)$.

Dessa maneira, no que se refere ao modelo adotado por Vargas, $C M$ e $O G$ tomam posição muito diferente das assumidas pelo $O J$ e, especialmente, pelo $J B$, na medida em que os dois primeiros jornais identificam no mesmo uma alternativa viável para conciliar a defesa do "interesse nacional" com a participação da iniciativa privada no setor, embora o Correio se demonstre mais favorável à entrada do capital estrangeiro do que O Globo.

Conforme acompanhamos o desenrolar do processo, essa situação apresenta mudanças. E isso porque, quando o projeto do governo passa a ser atacado como "entreguista", os jornais tiveram que se posicionar sobre a empresa de Vargas diante de uma nova realidade, na qual a Petrobras passou a ser alvo de um pesado bombardeio dos defensores do monopólio estatal, com adesão da UDN.

Inicialmente, o $J B$ procura assumir uma linha conciliatória. Às posições que se defrontavam, apresenta como alternativa o modelo 
Petróleo, imprensa e luta pelo desenvolvimento econômico:...

de concessão ao capital estrangeiro adotado pelo México, que o jornal classifica como "nacionalista” (JB-09/05/52-1/4). Porém, quando a UDN reforça a tese monopolista, o $J B$ opta por uma estratégia de forte crítica ao "partido do Brigadeiro" e passa a defender, mesmo que parcialmente, a proposta de Vargas, afirmando que "o projeto do Governo [...] permite a conjugação de capitais do Estado e de particulares", já "o projeto da UDN. fecha a porta a qualquer outra iniciativa que não seja a do Estado, pelo monopólio estabelecido (JB-25/05/52-1/5). Em suma, nota-se que o $J B$ passa a ter maior tolerância com a proposta de Vargas diante do crescimento da fórmula monopolista, desviando a sua crítica "liberal" do programa do governo para a alternativa de monopólio estatal.

O Jornal toma uma das posturas mais duras contra a UDN, considerando a sua opção pelo monopólio pura "demagogia jacobina". Ao mesmo tempo, irá se posicionar favoravelmente ao programa do Executivo, tentando sustentá-lo como "nacionalista" e não "entreguista", em contraponto à campanha do "Petróleo é Nosso" ("Petrobras, empreendimento nacionalista", OJ-25/06/52-1/4). Entretanto, tenta diferenciar o "nacionalismo" de Vargas daquele sustentado pelo Cedpen como um "nacionalismo sadio", ou seja, que defende a independência econômica brasileira mas não nega a participação estrangeira no progresso do país ("Bandeira nacionalista", OJ-27/06/52-1/4). Ademais, toma uma posição favorável à opção varguista quando compara o modelo da Petrobras ao "exemplo de Volta Redonda", afirmando que "[...] a sociedade de capitais mistos, com as seguranças de que está cercado o funcionamento da empresa, é o ideal com garantia de que se alcancem os objetivos econômicos da iniciativa (OJ-05/09/52-1/4).

Já o CM é o diário que mais se preocupa em atacar os avanços do monopólio estatal. Posicionando-se abertamente contra a tese monopolista, acusa os militantes do Cedpen de fazerem o "jogo de Moscou" (CM-17/05/52-1/1) e condena a UDN por demagogia e politicagem ao adotar, apenas para se opor à Vargas, uma tese que nunca defendera (CM-11/05/52-1/1). No que se refere ao programa a ser adotado, o $C M$, mesmo ainda não descartando investimentos externos, estabelecerá várias restrições à entrada dos trustes estrangeiros no país, pregando a necessidade de se controlar estritamente as futuras empresas "alienígenas": 


\section{Luis Carlos Passos Martins}

Sustenta-se, a nosso ver, com razão, que um país pobre como o Brasil deve reservar-se, na medida do possível, os lucros da exploração do petróleo, evitando que o controle privado possa dar aplicação antissocial à indústria petrolífera ou ensejar perigosas interferências de companhias estrangeiras (CM-23/04/52-1/1).

O CM passa também a assumir a defesa não apenas do programa de Vargas, mas do modelo que ele propôs: "O projeto da Petrobras, ora no Congresso, tem (o mérito de) libertar o país de sua dependência, em petróleo e derivados, do abastecimento estrangeiro, ao mesmo tempo que visa a canalizar para uma empresa nacional, os lucros da indústria petrolífera" ("A Petrobras", CM-20/04/52-1/4). Além disso, o jornal não apresenta receios sobre uma possível ampliação excessiva do papel do Estado na economia derivada da criação de uma estatal de capital misto (CM-17/04/52-1/4).

Em O Globo, encontramos uma postura semelhante à do Correio. Esse jornal continua a defender a empresa de Vargas, afirmando que ela é perfeitamente adequada à realidade brasileira:

Desde que o Governo apresentou ao Congresso o seu projeto para a solução do caso do petróleo, o "GLOBO tomou posição favorável ao mesmo, por isso que a criação da Petrobras estava resguardada a soberania brasileira na exploração do precioso combustivel”, sem o perigo da intervenção estrangeira que, em outros países, tem provocado crises e conflitos. A "sociedade mista, em que o Governo possui a maioria, é uma solução" (OG-08/05/52-1/1).

Novamente encontramos argumentos que defendem tanto os limites ao capital externo no setor petrolífero quanto o modelo de empresa proposto pelo governo, sem que este represente ou esteja associado ao "estatismo" ou ao "dirigismo econômico", conceitos que surgem vinculados ao monopólio do petróleo. Ademais, na sequência, o jornal também não poupa críticas à UDN: "Mas, e a UDN? Por que se une aos inimigos da iniciativa privada em favor do monopólio? Por que abre contradição tão flagrante no seu pensamento, em simples obséquio a mesquinhas manobras parlamentares?" 
Petróleo, imprensa e luta pelo desenvolvimento econômico:...

Por fim, resta analisar a reação dos periódicos estudados quando o governo aceita o monopólio estatal parcial do petróleo em seu programa.

No $J B$, não encontramos destaques às negociações e à aceitação da tese do monopólio pelo governo. Quando a estatal foi criada, esse impresso se limitava a relatar o acontecimento em seu noticiário e a condenar o modelo de empresa adotado, repetindo basicamente a argumentação que usou durante todo o episódio (JB-04/10/53-1/6; JB-06/10/53-1/5).

O Jornal toma um caminho semelhante. Ele opta por um significativo silêncio em relatar a criação da Petrobras, que não aparece em seu noticiário, em outubro de 1953. Antes, porém, já havia criticado o governo por sua "capitulação não só em relação aos aspectos práticos do projeto como ainda dos pontos de vista doutrinários em que se baseava". Condenando Vargas por deixar-se derrotar pela "politiquice da UDN", afirma: "Nada resta da Petrobras, qual saiu do Palácio do Catete, em nome do governo, como a solução mais lógica e conveniente do nosso problema do petróleo. O que sair agora da Câmara não será obra do presidente Getúlio Vargas, mas dos seus mais duros adversários" (OJ-27/07/52-1/4).

$O$ Globo adota atitude parecida aos demais jornais, também dando pouco espaço à aprovação final da Petrobras. Mas, durante o processo em que o governo negocia com a UDN o acordo do monopólio, não poupa críticas a ambos e continua defendendo o projeto original do Executivo, dando atenção especial à necessidade de a iniciativa privada nacional participar do empreendimento ("O fim melancólico da batalha do petróleo", OG-03/09/52-1/1).

Já o CM toma posição ainda mais aguda. O jornal acompanha todo o processo de discussão do programa e tece severas críticas a Vargas por ter abandonado a fórmula original do Executivo. Durante os debates no Senado, volta a ressaltar as vantagens do programa original varguista:

A posição originariamente sustentada pelo governo definiase a si própria como representando um nacionalismo moderado. Advogava-se o nacionalismo como meio de defesa contra a pressão dos trustes. Mas todos o desejavam moderado, a fim de não privar a iniciativa do capital estrangeiro minoritário $(C M-21 / 11 / 52-1 / 4)$. 
Quando o monopólio é finalmente aprovado, o $C M$ demonstra toda a sua decepção, considerando o resultado como uma prova do fracasso das elites brasileiras e um risco à própria democracia:

Vemos nisso um triste sinal da demissão das elites. Demissão da própria condição essencial delas, para que se constituam ou se legitimem como elites. E, quando as elites não se afirmam, não se impõem, não se fazem valer pela inteligência pela cultura, pela coragem que lhes dão as próprias virtudes, a democracia está em perigo (CM-15/09/53-1/4).

\section{Conclusões}

O processo de criação da Petrobras é longo e polêmico, mas a sua análise permite um bom campo de observação para entendermos melhor a complexa dinâmica das relações entre imprensa e política no período estudado e seu papel relativo na delimitação da problemática legítima em termos de programas econômicos.

Em primeiro lugar, no que se refere à relação entre os jornais e o universo político, notamos que os primeiros adotam sinuosas e distintas estratégicas, conforme os agentes do segundo se movem taticamente em torno do tema. Logo no início, o JB, por exemplo, demonstra muita resistência com a fórmula original de Vargas, mas passa a apoiá-la na medida em que os defensores do monopólio estatal do petróleo ganham terreno, especialmente com a adesão da UDN. O que se justifica diante da acusação desta proposta não apenas de "estatismo" mas também de "comunista". Dessa maneira, quando Vargas cede à tese monopolista, o $J B$ volta-se totalmente contra o presidente da República.

Com O Jornal ocorre uma situação parecida, embora a estratégia desse diário seja uma resultante de demandas ainda mais complexas: no lançamento do programa, não defende o modelo indicado pelo governo, tendo em vista o seu próprio compromisso tradicional com a necessidade do capital externo na indústria petrolífera; entretanto, a sua aproximação política com Vargas o leva a endossar a proposta da Petrobras com base na própria imagem pretendida pelo governo, ou seja, como uma alternativa "nacionalista". 
Petróleo, imprensa e luta pelo desenvolvimento econômico:...

Quando a tese do monopólio começa a ganhar força, o periódico então combina o apoio ao governo com o endosso ao modelo da empresa de economia mista, entrando em uma verdadeira luta pela definição do sentido mais legítimo do "nacionalismo" com os monopolistas. A aceitação, por parte de Vargas, do monopólio parcial na empresa leva a um dos raros momentos de distanciamento entre O Jornal e o presidente da República em termos econômicos.

O Correio da Manhã e O Globo demonstraram, em termos programáticos, uma linha de ação mais linear, na medida em que sempre defenderam o modelo originalmente apresentado por Vargas. Afastaram-se e distanciaram-se de Getúlio conforme ele se afastava ou se distanciava de seu próprio programa, acabando por condenar o presidente por não ter sido coerente com a sua própria proposta, em favor de "conveniências políticas".

Em relação a esta última questão, é interessante ressaltar que nenhum dos jornais pesquisados seguiu os passos da UDN, partido com o qual ao menos três periódicos eram mais identificados $(O G, C M$ e $J B)$. Muito pelo contrário, condenaram pesadamente o partido por escolher uma tese estranha ao seu programa no intuito de ganhar "dividendos políticos", fazendo com que o próprio Vargas se desvirtuasse do rumo "correto".

Essa constatação é fundamental, não só para matizar as interpretações que colocam a grande imprensa carioca como fazendo uma oposição intransigente ao Segundo Governo Vargas ou mesmo sendo udenista, mas também para indicar como não havia uma mera relação de subordinação entre o universo político e o jornalístico, como defende ou dá a entender parte da historiografia (LAURENZA, 1998; RIBEIRO, 2007; SODRÉ, 1983).

Em segundo lugar, em termos de doutrinas econômicas, vemos que os jornais tomaram posições distintas, sendo dois (JB e OJ) mais resistentes à proposta de uma empresa estatal de economia mista e mais adeptos à participação do capital estrangeiro, enquanto os demais $(O G$ e $C M)$ aceitaram e até defenderam a criação da "empresa mista" como um modelo adequado ou ideal para resolver o problema do petróleo.

Esta constatação é de fundamental interesse porque também contraria a visão tradicional firmada pela bibliografia de que os grandes jornais teriam sido intransigentes na crítica ao projeto da Petrobras. $\mathrm{Na}$ verdade, foram críticos à proposta do monopólio estatal do 
petróleo, mas não ao projeto original do governo que, no mínimo, dividiu a posição dos periódicos pesquisados. $\mathrm{O}$ mais surpreendente fica por conta da posição de O Globo. Classificado como neoliberal e defensor do capital estrangeiro, foi o impresso que mais defendeu o programa original de Vargas e o que mais se opôs à entrada dos recursos alienígenas nesse setor.

Em consequência, o estudo aqui apresentado nos instiga a inferir que a classificação da grande imprensa carioca na conjuntura em questão, em termos de doutrina econômica, como liberal ou neoliberal é, no mínimo, insuficiente. Como podemos perceber quando notamos que, ao menos dois dos jornais pesquisados $(C M$ e $O G$ ), admitiam um grau de participação do Estado na economia bem superior àquele aceito pelos liberais do período, como Eugênio Gudin (1977).

Constatação que se reforça quando acrescentamos que ela não é exclusiva ao caso do petróleo e também aparece no posicionamento mais geral desses jornais sobre outros temas do programa econômico de Vargas. Embora não seja possível nas dimensões desse artigo estender-se sobre esse tema, devemos salientar que com exceção do $J B$, que ainda defendia a especialização do país como produtor primário, os demais periódicos envolveram-se abertamente na pregação do projeto desenvolvimentista, baseado na industrialização com o apoio estatal e no planejamento econômico, numa posição muito próxima àquela corrente que Bielschowsky define como desenvolvimentismo não-nacionalista (2002, p. 8). Como claro, por exemplo, neste trecho de um editorial do $C M$ defendendo o planejamento econômico:

[...] deve-se reconhecer como regra pacífica a possibilidade e, mais que esta, a necessidade do entrosamento entre a intervenção planejadora do Estado e a livre iniciativa das empresas. Somente pela adoção de um plano se pode proceder em prazo curto e em bases econômicas à recuperação de uma economia subdesenvolvida. [...] A primeira tarefa da Comissão de Desenvolvimento Industrial será, portanto, elaborar um plano para a industrialização. Cabe ao governo completar a iniciativa, estendendo o planejamento aos outros ramos da economia, mediante um planejamento geral ("Indústria e planejamento", CM-15/08/51-1/4). 
Petróleo, imprensa e luta pelo desenvolvimento econômico:...

Ou por este editorial de $O$ Globo defendendo a industrialização brasileira com base no protecionismo:

Ninguém ignora que a indústria nacional, conforme frisou há
tempos o deputado Euvaldo Lodi, (carece) de proteção (esta-
tal). Na verdade, não possuímos um sistema tarifário prote-
cionista como os mais importantes países o possuem. Nossa
indústria precisa de defesa, de estímulo e de compreensão
[...]. Precisamos incentivar a produção do que não produ-
zimos ou produzimos insuficientemente, não permitindo
que se venham a instalar aqui indústrias em concorrência
com as já existentes ("Rumos para a nossa expansão indus-
trial", $O G-28 / 07 / 52-1 / 2$ ).

De outra parte, essas próprias passagens nos indicam que o programa econômico levado adiante por Vargas - que tinha na Petrobras original um dos seus pontos basilares - não era exclusivamente um projeto varguista, mas aproxima-se muito das propostas defendidas pela Cepal e, especialmente, pelos líderes empresariais ligados à CNI. Logo, o projeto endossado por boa parte desses jornais é também sustentado pelo setor mais moderno da burguesia nacional, pela intelectualidade brasileira, pelas classes médias urbanas e mesmo parte do operariado fabril, beneficiados com esse processo de modernização (BIELCHOWISKY, 2000; LEOPOLDI, 2002; FONSECA, 1985, 2002).

Todavia, não podemos falar propriamente de uma imprensa como mero porta-voz de grupos econômicos. Mais do que isso, seguindo aqui as indicações de Abreu (1996), esses jornais procuravam se colocar como intérpretes da nova realidade pela qual passava o Brasil, usando criativamente o debate da economia política na interpretação da mesma. Para tanto, o liberalismo econômico se demonstra cada vez mais inadequado para oferecer categorias intelectuais apropriadas à compreensão de um país em amplo processo de industrialização e urbanização acelerada. Assim, mais do que reprodução dos novos esquemas conceituais, há uma apropriação ativa por parte desses jornais das novas ideias desenvolvimentistas que estavam emergindo no período, que nem sempre se sobrepõe 
ao discurso empresarial. Até porque, não devemos esquecer que os periódicos da grande imprensa carioca também eram beneficiários do próprio projeto desenvolvimentista: urbanização, alfabetização, aumento dos salários e do emprego industrial e urbano incrementavam a renda dos impressos em publicidade e o seu público leitor, o que permitia maior força econômica e maior peso na esfera de debates àqueles que se adaptassem as essas mudanças estruturais (SÉGUIN DE HONS, 1985; RIBEIRO, 2004).

Nos anos 50, o discurso que associava Nação, Nacionalismo, industrialização e setores estratégicos da economia (metalurgia, combustíveis) também ganhava cada vez mais densidade simbólica, permitindo ganhos de legitimidade a quem dele se apropriasse na esfera pública. Em relação propriamente ao tema do petróleo, nessa década, já havia no Brasil uma longa tradição - envolvendo desde escritores do peso de um Monteiro Lobato, até militares como o general Horta Barbosa - que associava muito eficazmente a exploração do "nosso ouro negro" a uma verdadeira questão de "soberania nacional". ${ }^{13}$ Dessa maneira, a tomada de posição sobre esse tema obrigava os jornais a levar em consideração toda essa carga simbólica. Diferentemente do que seria permitido a um economista acadêmico, o discurso jornalístico sobre um tema de economia exigia a incorporação desses elementos, exteriores às teorias econômicas, mas fundamentais na persuasão e na construção da legitimidade dos jornais perante o público leitor.

\section{OIL, PRESS AND THE FIGHT FOR ECONOMIC DEVELOPMENT: CARIOCA “LIBERAL" NEWSPAPERS AND THE ECONOMIC POLICY OF THE SECOND VARGAS ADMINISTRATION}

Abstract: The following paper will analyze how the liberal press from Rio de Janeiro positioned itself on the issue of the Petrobras' ( Brazilian State Oil company) creation (1951-1953). The publications about to be analyzed are: O Globo, O Jornal, Correio da Manha and Jornal do Brasil. The creation of Petrobras was extremely controversial at that time and increased public debate about the country's development and the role of the State and foreign capital in the brazilian economy. Moreover, a huge political dispute surrounded all that, where the government proposal was considered to be a "sell off" by the liberal opposition due to the fact that the initial project of petrobras's creation did not envolve full 
government monopoly. UDN was in favor of that at first, but changed its mind on political grounds to hit Vargas and his government. Because of that, this is an important topic to understand the positioning of the liberal journals. not only on politics, but also on economic issues such as liberalism, nationalism and development. In the end, this paper will allow historians to better understand the traditional interpretations of historiography on that matter and to evaluate the relation between press and politics during the early 1950's.

Keywords: Press. Vargas. Developmentalism. Liberalism.

\section{Notas}

${ }^{1}$ Sobre essa "oposição intransigente", consultar SILVA (1978) e SODRÉ (1983). Já em relação à enxurrada de acusações a Getúlio, podemos consultar: (ABREU; LATTMAN-WELTMAN, 1994) e (RODRIGUES, 1999).

${ }^{2}$ Escrevo o termo "liberal" entre aspas porque, como será esclarecido mais além, esse conceito é bastante impreciso para definir satisfatoriamente o alinhamento doutrinário em termos de política econômica da imprensa brasileira na conjuntura em questão. Por ora, desejo apenas ressaltar que a maior parte dos jornais citados, assim como o grosso da grande imprensa brasileira, era identificada ou se auto identificava como liberal.

${ }^{3}$ Sobre o conceito de desenvolvimentismo, consultar (BIELSCHOWSKY, 2000, p. 7).

${ }^{4}$ Ver, por exemplo, (RODRIGUES, 1999) e (HAUSSEN, 2001).

${ }^{5}$ Para simplificar, iremos nomear o Dicionário Histórico-Biográfico Brasileiro como DHBB.

${ }^{6}$ Grifos nossos.

${ }^{7}$ A AEPR era composta por cerca de oito técnicos permanentes, inicialmente liderados por Rômulo Almeida e, depois, por Jesus Pereira Soares. Ela estava subordinada ao Gabinete Civil e foi criada para dar assistência direta ao presidente da República na elaboração de projetos, ficando sob sua responsabilidade os programas mais significativos do governo na área de energia, como o do carvão, o do petróleo e da eletricidade (SANTOS, 2010).

${ }^{8}$ O Cedpen teve origem no Centro de Estudo e Defesa do Petróleo (CEDP), criado em 1948, no Rio de Janeiro, em reação ao projeto do governo Dutra do Estatuto do Petróleo. Com o tempo, estendeu as suas atividades por todo o país, sempre em defesa do monopólio integral do petróleo, num movimento conhecido como Campanha do Petróleo. 


\section{Luis Carlos Passos Martins}

${ }^{9}$ Para identificar as citações dos jornais empregamos um sistema de referência que permite indicar, afora a data e a página, também o gênero do material analisado. Desta forma, cada notação compreende uma sigla para o jornal citado $(O J=O$ Jornal; $O G=O$ Globo; $C M=$ Correio da Manhã e JB = Jornal do Brasil), seguida da data (dd/mm/aa) e, depois do hífen, da localização no jornal (são dois números: o primeiro indicando o caderno e o segundo indicando a página). Sendo assim, uma referência como $C M-12 / 05 / 52-1 / 3$ indica que é o referido material corresponde ao jornal Correio da Manhã, publicado na página 3 da primeira sessão ou caderno, no dia 12 de maio de 1952. Em geral, o material citado corresponde prioritariamente a editoriais. Quando não for o caso, será devidamente indicado.

${ }^{10}$ A reportagem correspondente ao lançamento do programa ocupa espaço apenas no interior do caderno 1 e praticamente se reduz a reproduzir a Mensagem do presidente que apresentou os programas ("Um grande empreendimento econômico lançado no Brasil - Visando solucionar o problema do petróleo, o Chefe do Governo envia mensagem ao Congresso Nacional propondo a organização de uma empresa mista de capital público e privado para a industrialização dessa fonte de riqueza do País - A integra da mensagem presidencial.”, JB-07/12/51, 1/9).

${ }^{11}$ Como podemos notar pelo título da reportagem principal ("Emancipação econômica com o petróleo") e do subtítulo que a acompanha: "vargas propõe a exploração industrial: Participação do capital privado, mas livre da influência dos monopólios - Quatro bilhões inicialmente e dez bilhões dentro de cinco anos - No máximo vinte mil ações para as pessoas físicas e duzentas mil para as pessoas jurídicas" (OJ, 07/12/51-1/4).

12 Por eles não resolverem o problema da colaboração da técnica estrangeira necessária para a pesquisa do petróleo diante dos possíveis boicotes dos trusts ao novo empreendimento sob o controle do Estado. Ver: "Petróleo" (CM-08/12/511/4) e "Técnica e investimento" (CM-09/12/51-1/4).

13 Ideias que, por exemplo, Monteiro Lobato defendia desde os anos $30 \mathrm{em}$ diversos artigos e que acabaram sendo reunidas em um livro, de enorme repercussão nas décadas de 40 e 50, intitulado O Escândalo do Petróleo e do Ferro.

\section{Jornais Citados:}

Correio da Manhã. Janeiro de 1951 a outubro de 1953.

O Globo. Janeiro de 1951 a outubro de 1953.

O Jornal. Janeiro de 1951 a outubro de 1953.

Jornal do Brasil. Janeiro de 1951 a outubro de 1953.

Anos 90, Porto Alegre, v. 19, n. 36, p. 199-219, dez. 2012 
Petróleo, imprensa e luta pelo desenvolvimento econômico:...

\section{Referências}

ABREU, Alzira Alves de et al. (Coord). Dicionário Histórico-Biográfico Brasileiro: Pós 1930. 2. ed. rev. e atual. Rio de Janeiro: CPDOC/FGV, 2001.

A; LATTMAN-WELTMAN, Fernando. Fechando o cerco: a imprensa e a crise de agosto de 1954. In: GOMES, Ângela (Org.). Vargas e a crise dos anos 50. Rio de Janeiro: Relume-Dumará, 1994.

- A Imprensa em Transição: O Jornalismo Brasileiro nos anos 50. Rio de Janeiro Fundação Getúlio Vargas, 1996.

BASTOS, Pedro Paulo. A dependência em progresso: fragilidade financeira, vulnerabilidade comercial e crises cambiais no Brasil (1890-1954). Tese de Doutorado Unicamp - Campinas - SP - 2001 (s.n.). Disponível em: <http:/ / libdigi.unicamp. $\mathrm{br} /$ document $/$ ?code $=$ vtls000232699>

BIELSCHOWSKY, Ricardo. Pensamento econômico brasileiro: o ciclo ideológico do desenvolvimento. 4. ed. Rio de Janeiro: Contraponto, 2000.

COHN, Gabriel. Petróleo e Nacionalismo. São Paulo: Difusão Européia do Livro, 1968. (Coleção Corpo e Alma do Brasil).

DRAIBE, Sônia. Rumos e metamorfoses - Estado e industrialização no Brasil: 1930/ 1960. Rio de Janeiro : Paz e Terra, 1985.

FONSECA, Pedro Cezar Dutra. Nacionalismo e Economia: o segundo governo Vargas. In: SZMRECSÁNYI, Tamás; SUZIGAN, Wilson (Org.) História Econômica do Brasil Contemporâneo. 2. ed São Paulo - HUCITEC/Associação Brasileira de Pesquisadores em História Econômica/Editora da Universidade de São Paulo/ Imprensa Oficial, 2002.

. Vargas: O capitalismo em construção: 1906-1954. Ed. Brasiliense : São Paulo, 1987.

GUDIN, Eugênio. Rumos da politica econômica. In.: SIMONSEN, Roberto Cochrane.. A controvérsia do planejamento na economia brasileira. Rio de Janeiro: IPEA, 1977.

HAUSSEN, Dóris. Rádio e Política: Tempos de Vargas e Perón. 2. ed. Porto Alegre: EDIPUCRS, 2001

LAURENZA, Ana M. A. Lacerda $\times$ Wainer: o Corvo e o Bessarabiano. 2. ed., São Paulo: Ed. SENAC, 1998.

LEOPOLDI, Maria Antonieta Parahyba Leopoldi. Política e interesses na industrialização brasileira: As associações industriais, a política econômica e o Estado. São Paulo: Paz e Terra: 2000. 


\section{Luis Carlos Passos Martins}

MIRANDA, Maria Tibiriçá. O Petróleo é Nosso: a luta contra o "entreguismo" pelo monopólio estatal (1947-1953)(1953-1981). Petrópolis: Vozes, 1983.

PEREIRA, Jesus S. Petróleo, Energia Elétrica, Siderurgia: A luta pela emancipação. Rio de Janeiro: Paz e Terra, 1975.

RIBEIRO, Lavina M. Impensa e Espaço Público: A institucionalização do jornalismo no Brasil (1808-1964). Rio de Janeiro: E-Papers, 2004.

RODRIGUES. Mônica S. Pelas Lentes da Tupi: uma leitura do campo jornalístico no final da Era Vargas. Rio de Janeiro: UFRJ/IFCS, 1999 (mimeo)

SANTOS, Renata Belzunces dos. A Assessoria econômica da presidência da República: contribuição para a interpretação do Segundo Governo Getúlio Vargas (1951-1954). Campinas: Instituto de Economia, 2006. (Dissertação de mestrado). Disponível em: $<$ http:/ / cutter.unicamp.br/document/?code $=$ vtls000402434\&fd $=\mathrm{y}>$ Acesso em: 22 nov. de 2010.

SÉGUIN DE HONS, André de. Le Brésil: Presse et historie - 1930-1985. Paris: L'Harmattan, 1985.

SILVA, Hélio. 1954: Um tiro no coração. Rio de Janeiro: Civilização Brasileira, 1978.

SKIDMORE, Thomas. Brasil: de Getúlio Vargas a Castelo Branco (1930-1964). 11. reimp., Rio de Janeiro: Paz e Terra, 1996.

SODRÉ, Nelson Werneck. Historia da imprensa no Brasil. São Paulo: Martins Fontes, 1983.

WIRTH, John D. A Politica do desenvolvimento na Era de Vargas. Trad. de Jefferson Barata. Rio de Janeiro: Fundação Getúlio Vargas, 1973.

Recebido em 30/07/2012

Aprovado em: 27/11/2012

Anos 90, Porto Alegre, v. 19, n. 36, p. 199-219, dez. 2012 